\title{
Historic Gardens as Places of Conflicting Values
}

Mateusz Salwa (Warsaw University; Warsaw, Poland)

\section{Introduction ${ }^{1}$}

The aim of this article is to present historical gardens as phenomena inevitably pervaded by an ongoing clash of values that can be characterized by a theory proposed by Austrian art historian Alois Riegl, one of the founders of the modern theory of restoration of historical monuments. The conflict stems from the twofold character of gardens where art (or in broader terms: culture) and nature are combined, resulting in a tension between a tendency, pertaining to culture, to remain static and the changeability inherent in nature. In my view, the main theoretical and practical issues about gardens is that they tend to be understood as embodiments of a gardener's or a landscape architect's intentions, which makes us think of and treat them as possessing a fixed shape and meaning that we should protect from any changes through time. However, what severely undermines this perspective is the ever-changing vegetation employed in gardens. Nature, being dynamic, makes the notion of gardens possessing a fixed form and meaning quite dubious: do we really see in, for instance, the Versailles Gardens, what Louis XIV or Balzac saw? Do we experience and interpret them in the same manner they did? It is true that whenever we go to such places we somehow tend to believe that these are the same gardens that people from the past used to walk in. Nevertheless, we should seek the identity of a garden somewhere other than in its shape or meaning.

This tension, which in my view is essential to understanding and protecting gardens, may be described in many ways. In this article I will focus on the clash of two perspectives. The first treats historic gardens as "timeless," which means that each garden has an original shape that has to be conserved and preserved. Its most important values are artistic, wherein all the nonhuman elements (e.g., plants and animals) have to be subsumed under the "timeless" artistic structure. The second perspective sees gardens as living areas. On the one hand, a garden's actual shape and meaning result from its cultural and natural history from its creation. On other hand, its natural value

1 This article was prepared thanks to the support of the National Science Centre (Poland) (grant: No. 2011/01/D/HS1/01661). The author would like to express his gratitude to the two anonymous reviewers whose comments were very inspiring and contributed much to the text. 
(arising from self-seeded plants, wild animals, natural processes, etc.) is appreciated as the source of its social importance, even if the present conditions of a garden fail to fit with the original plan, or even undermine the very idea of a garden. One may object here that equating the dichotomy of art/nature with the dichotomy of static/dynamic is not legitimate, since art need not be static (as in, e.g., the performing arts). One can, however, reply that what is at stake in the context of historic gardens is the "traditional" idea of artwork (e.g., as a Baroque garden is analogous to a Baroque painting or poem). Therefore, the first of the two perspectives treats gardens not as living performances but very much like still paintings, classical architecture, or even texts, in the sense that any change, even if inevitable, is unwelcomed, and as such is external. According to the other perspective--in which toutes proportions gardées can be called "ecological"-one should not prevent changes resulting from natural processes, although one might seek to mitigate them. The question arises as to whether we can maintain a garden in a way that would strike a balance between the two opposing points of view by focusing on the ideas acceptable to both.

Gardens are always human-made; they are places where the natural environment is transformed according to a person's aesthetic experience and expectations. To a large extent, a garden embodies its creator's aesthetic attitude toward her environment, which, of course, does not necessarily exclude other, such as practical or scientific, possible interests in it. On the other hand, even if one thinks of gardens as highly humanized environments, one cannot disregard the natural, or non-human, elements such as the soil, weeds, and insects.

The analyses of gardens should, therefore, be placed at the intersection of aesthetics of art and aesthetics of nature, for neither of these perspectives alone fully grasps the idea or essence of gardens. Yet gardens, it is widely acknowledged (see Miller 1993; Ross 1998; Cooper 2006), are conceptually precisely between art and nature-or to put it differently: they are art-andnature.

In the vast body of literature on landscapes, one comes across a variety of definitions of the notion of landscape; nevertheless, they seem to share a common denominator. Namely, a landscape exists only insofar as it is created by humans either by their "material" actions shaping (intentionally or not) their surroundings, or by their aesthetic attitude through which the environment is experienced and appreciated as an aesthetic object. ${ }^{2}$ As Augustin Berque states in a Kantian vein, landscape is the world itself as well as the way it is perceived and conceived (Berque 2000). Interestingly, this duality has been acknowledged by the European Landscape Convention: "'Landscape' means an area, as perceived by people, whose character is the result of the

${ }^{2}$ For an overview of two different traditions, see Assunto 2005; Berleant 2005, 1-100. 
action and interaction of natural and/or human factors" (ELC 2000, § I.1; see also Antrop 2013, 18).

Given these premises, it seems reasonable to treat gardens as particular tokens of landscape: tokens that make the latter's double character more tangible if for no other reason than at least because gardens-as has been said-are the fruit of intentional human fashioning of a well-defined piece of nature, and because they are somewhat more concrete than a landscape as such, which is "a vague concept and in reality has fuzzy edges" (Brook 2013, 109). Consequently, one can observe at least some of the problems that are characteristic of landscapes in general, especially when their historical or temporal dimensions are at stake. Thus, the conflict of values within a garden may be seen as a scaled down example of the same clash occurring at the more general level of landscapes. These clashes are, above all, discords between different ways of thinking about landscapes, either merely divergent or more seriously colliding. It goes without saying that these conceptual quarrels may have deep-sometimes irreversible-impacts on the landscapes themselves. It is in this sense, too, that the problems that gardens pose for restoration theory and practice may help us understand analogous topics concerned with landscapes (Anthony 1996).

It is noteworthy that historical gardens and parks are very particular "objects" whose restoration, conservation, or preservation raises specific problems (see e.g., Mackellar Goulty 1993). These stem from the fact that although gardens are thought to be artifacts, and consequently should be managed in ways similar to how buildings or paintings (to name two fields to which gardens are often compared) are maintained, they are, nevertheless, nature-based. This acknowledgement makes the uniquely art-centered perspective highly debatable. In other words, I argue that caring for historical gardens ought to involve multiple dimensions too; in particular, it should attempt to find answers to questions discussed in the field of art restoration and conservation as well as that of ecological restoration. The latter is indispensable because it can offer practical and theoretical instruments that allow us to cope with plants and hence properly value a garden's natural dimension. But most importantly, it is vital because it addresses directly issues such as the authenticity of restored ecosystems in relation to their continuity. These interests can in turn be fruitfully extrapolated onto the field of garden restoration or aligned with phenomenological analyses of such themes as the sense of place and its correlates, authenticity and identity, as well as the key category for gardens-genius loci. This is also the reason why Riegl's theory proves to be so thought-inspiring: it offers an interesting framework that comprises all of these mentioned elements, while at the same time it succeeds in maintaining a dialectical tension between them without committing gross oversimplifications. 


\section{The Krasinski Garden Debate}

To illustrate my argument, I turn to the example of one of the historical public parks situated in the heart of Warsaw: the Krasinski Garden. Its historical importance is beyond question, even though during the centuries it underwent so many deep changes that there is nothing left of its original form, including its botanic elements. After a relatively long period of neglect, the municipal authorities decided that the garden should be restored. The restoration process-which began autumn of 2012 and was supposed to end by summer of 2014-has become one of the most hotly debated topics in recent years in Warsaw. For the past twenty years, Warsaw has been experiencing rapid growth and modernization and-as is usually the case-this process has had its ups and downs, but in very few other similar circumstances could one witness similarly heated reactions.

Before discussing the debate it is useful to offer a short outline of the history of the Krasinski Garden (Krasinski 2013). It was founded in the $17^{\text {th }}$ century as a Baroque palace garden belonging to one of the major Polish noble families-the Krasinscy. During the following 250 years it was restructured several times according to constantly changing tastes, arriving at its near final shape at the end of $19^{\text {th }}$ century. It is this form, designed by the leading Warsaw landscape architect of that time, Franciszek Szanior, that the local authorities and architects responsible for the restoration work intend to revive. In the second half of the $18^{\text {th }}$ century the garden was opened to the public, making it one of the first ever public gardens in Warsaw. Over the next 100 years it was one of the most fashionable places sought out by city dwellers. At the time of the Second World War-in particular, during the Warsaw Uprising of 1944the Krasinski Garden became the backdrop of intense battles. It was severely destroyed and partially used as a burial ground. Moreover, it was located in the Ghetto neighborhood. After the war its area was doubled, and until recently it was also a place where trees taken from, for example, the metro construction sites, were moved to and planted.

It was clear from the outset that given its poor condition, the garden was beyond doubt in need of restoration. It was in this context that the opinions of the proponents and opponents of the restoration met; though this is also where the accord between them ended. As already mentioned, no other restoration project in Warsaw was as controversial as this one. Although one would have expected such an enterprise to be heartedly welcomed by everyone but perhaps some solitary malcontents, the project proved to be extremely contentious. The controversies led to a series of newspaper articles, letters from readers, public hearings, debates, petitions, and-what is even more interesting-social activism. The latter included not only the typical hanging of banners, but more symbolic actions as well. For example, because the first stage of the work, the extensive clearing of vegetation, took place in proximity of All Saints' Day, collective action took the form of lighting candles put on the 
resulting tree stumps - thereby keeping a kind of collective vigil over the dead trees-and laying flowers on the spot where a dead owl was found, setting its ephemeral cenotaph. All of this symbolism may appear dull, kitschy, or strained, but nonetheless it had never before been utilized for non-human beings, at least in Warsaw. Paradoxically, a badly maintained garden, seen as an endangered "entity," managed to create a community whose primary concern was a sort of amateur or naïve ecology (as opposed to the art-historical issues) in a much more effective way than many artistic projects did and will probably ever do. ${ }^{3}$

Assuming that everyone involved in this situation has been moved by an interest in improving the garden and enhancing its values, the core of the conflict seems to lie in two divergent ideas as to what a garden is and should be. To simplify, it seems that the division is between the art-historical and the social-ecological perspectives. ${ }^{4}$ The aim here is to outline the most important and general assumptions, which will help us better understand the conflict of values in this case. Clearly, there exists a continuum of opinions; what is sketched here is an attempt to clarify the heart of the disagreement, which admittedly (though usefully) creates a pair of overly idealized extremes.

On one side of the debate were landscape architects and historians convinced that a garden is a sort of architectural artwork-in this case one dating back to the end of the $19^{\text {th }}$ century. The proponents of such a view usually claim that once a garden is created, a particular form of it is assumed. This form could, in the course of time, undergo alterations external to its "original" structure and is therefore removable (e.g., it is possible to replace decaying plants with new ones or to get rid of those that were not included in the architect's project but grew up later on). A garden, then, is treated as a purely cultural phenomenon - one could say, a monument-in which its natural dimension is indispensable but of relatively low importance insofar as it is part of the garden's essential features. Those who hold this view seem to imply that even though there can be no garden without plants, and we indeed can

\footnotetext{
${ }^{3}$ It goes without saying that it would be a gross mistake to idealize this situation and interpret it in a dichotomous way (nature vs. culture, ingenuous nature vs. cynical politics, etc.), for there was much politicizing, obstinance, and intractability on both sides, as well as a sheer fear of change on the opponents' part, not to mention the errors committed by local authorities who either arrogantly dismissed the opinion of the local community, nature lovers, and everyday visitors or tried to persuade the disputants in such an unskillful manner as to provoke their exaggerated discontent. I leave aside practical issues such as questions of whether gardens should be fenced, closed at night, or surveilled.

4 This division does not mean that local authorities who promoted the restoration were not concerned at all with ecological issues (e.g., they stated that the garden's flora had to be rejuvenated and replaced by new specimen for botanical reasons). And those who opted for leaving the garden largely untouched used aesthetic arguments as well, stating that this is what they like about the garden.
} 
appreciate them as beautiful and interesting (e.g., they offer us joy, healing, and greater biological knowledge), as soon as we move from the level of plants themselves to the garden as a whole (as the embodiment of an architect's idea), we must somehow treat nature as a mere medium. Like bricks in a building or colors in a painting, this medium can be replaced if needed without destroying the garden's authenticity.

On the other hand, the opponents of this approach embodied a sort of ecoactivist's perspective and claimed that a garden is an ecosystem, by which they meant that nature should take precedence over the historical considerations. They did not deny that the Krasinski Garden has historical value, but nevertheless they opted for the present conditions that offered possibilities for experiencing and appreciating nature, which is, they claimed, what really counts in a garden. As a result, even if nature in a garden is not pristine, they seemed to appreciate it as if it were in many respects wild; hence any intervention was necessarily seen as causing damage and, as a result, as something that should be kept to a minimum. ${ }^{5}$ The gardens, then, can be seen in this respect to be more like "natural monuments." This nature-centered perspective is not totally devoid of historical concerns. However, these had nothing to do with the concerns of the other side of the conflict.

Instead of treating the garden as a monument for the time it was created, what was emphasized as important by those taking the naturecentered view is the fact that some of the trees that were cut down in the process of restoration witnessed the war and survived it. In a way, the Krasinski Garden was thus conceived of as an ecosystem that fulfills the everyday needs of its users, while at the same time possessing a historical value that "grew up" along with the plants, making it important to save its continuity. Moreover, hardly anyone was of the opinion that the garden should not be maintained at all to let nature develop as it would.

It is not, then, the artificial character of the garden that is the bone of contention. What differentiates the two perspectives is the kind of values they attach to the garden. In many respects, the disagreement between the two sides of the debate is similar to that between intentionalist and anti-intentionalists in interpretation.

\section{The Garden as a Natural Monument}

In the past decades garden studies have developed in a conspicuous manner (see e.g., Conan 1999). The main discipline within which it originated was art history, which together with such fields as the history of ideas defined its direction. The garden is by and large treated as a work of art that has multiple

5 One may note that this kind of approach is to some extent naïve as it seems to unreflectively assume that what is best for nature is to leave it alone. 
meanings and therefore can be thought of as a representation (see e.g., Hunt $2000,76-115)$, which in turn can be analyzed on different levels. It is thought, therefore, that it is possible to establish a garden's original meaning and then decide whether we experience the garden in conformity with its creator's intention. However, there is no unanimity as to the meaning of gardens (see Treib 2011), for gardening is sometimes seen as an act of shaping nature and not of conferring meanings to it; for instance, a tree in a garden might be just a tree, and not necessarily a symbol of something else. What is more, doubts may arise as to whether the original meaning-if there is one-is still perceivable or readable, from which it follows that no comparison of meanings, such as those assumed by the garden historians, is viable. But even if we inevitably perceive gardens in different manners, our various perceptions cannot be judged as less authentic. And this is due to the fact that the discursive meaning to which garden historians allude is not the only one; we can speak of an emotional meaning as well, understood as an atmosphere that emerges from the interaction between a person and a garden, or rather from one's plain being in the garden (Cooper 2006, 47-53). None of this has much to do, if anything, with the garden creator's intentions.

Despite doubts about whether we can establish the proper meaning of a garden, and what it is, it is unquestionable that there is always some meaning. Roger Scruton (2000) is right when he poetically writes:

The garden is a surrounding space, not an open space. And that which grows and stands in it, grows and stands around us. Trees, for instance. A tree in a garden is not like a tree in a forest or a field. It is not simply there, growing from some scattered seed, accidental. It stands and watches, as I stand and watch. And although it does not move, the tree converses, in a sense, with those who walk beneath it ... (83).

In all likelihood, both parties of this conflict would reasonably agree that the Krasinski Garden is meaningful, although the concept of meaning they would employ would be quite vague and would be merely synonymous with "value." But whereas those opting for its restoration would claim that what counts is its historical or original value or meaning, those standing against it would rather defend the present-day values associated with the fact that they can spend some time in contact with nature that witnessed the history of the past century.

Now, it seems that either of these opinions taken alone is to a large extent untenable for they both miss something important, something that, paradoxically, lies at the core of the other. At the same time, these approaches are too contradictory to be flawlessly reconciled. Thus, as was mentioned with reference to Riegl, the only plausible way to explain this conundrum is to link the two views in a dialectical relationship that would correspond to the art/nature dialectics so essential to gardens (Crawford 1983). 
"Garden intentionalism," as discussed above, is partially justified. Gardens as such, like any other human-made objects, are propelled by their creator's intention or purpose. They were planned to offer their owners or visitors a place to perform specific activities or to behave in a particular way, and they were supposed to convey different social, political, etc., meanings. In a word, if we are to treat a piece of land as a garden, we must know (or assume) that there was an intent to make it a garden. This is what Scruton may have meant by stating that "a tree in a garden is not like a tree in a forest" (see also Leddy 1999). As a consequence, one might want to ruminate on gardens resorting solely to art-centered aesthetics. And it would in fact be possible, were it not for nature, which is unintentional and purposeless (at best we can talk of its "purposeless purposiveness," a la Kant). This is what restrains "garden intentionalism," not only conceptually but also practically. Even if we happen to be inclined to treat gardens as artworks, the ungovernable vegetal dimension of gardens makes them non-standard, or non-traditional, works of art. Gardens are not mere pieces of art for the same reasons that nature cannot be appreciated as art (see e.g., Carlson 2009; Parsons 2008), although our art appreciation may inform our aesthetic experience of nature (Moore 1999) and hence of gardens. In other words, traditional comparisons of gardens and architecture, or paintings, may be still inspiring, but they are certainly not obligatory or better than others.

As said above, one side in the debate seemed to treat the Krasinski Garden on par with the still remaining Baroque palace to which it once belonged. This approach, however, turns out not to be so evident. Let us now ponder the question of why gardens are artifacts whose artistic status is questionable. Most of the arguments tend to place the garden's natural aspect in the foreground (e.g., Miller 1993). For example, gardens are not objects standing in front of us like paintings but they surround us, which means that we are not spectators contemplating them from a distance, but rather we enter them and participate in them. Gardens are not stable, as they constantly change over the years and seasons according to the circular rhythms of biological processes of growth and decay-it is therefore difficult, if possible at all, to decide what the original shape of the garden was. In addition, gardens have a conspicuous phenomenal dimension for such factors as light, temperature, weather, etc. These factors play a crucial role in gardens: they are not external elements like lighting or temperature conditions in a museum, but are rather internal. As a result, it is unthinkable to enter the same garden twice: not only will the plants be older, but also our experience will be different. Moreover, it is far from obvious who should be credited with giving a garden its meaning-is it what was planned by the landscape architect or what came out of the interaction between him or her and nature? Or, is it what a visitor feels regardless of the creator's intentions? In contrast to a painter or an architect, a garden's creator has little control over her "medium." 
There are other arguments too that stem as much from considerations of art as from the field of ecological restoration (Elliot 1997): if all the plants are to be replaced, for example, then the continuity of a garden seems to be broken, raising questions about its authenticity. If we are to push this argument further, we could state that such a garden is fake.

The above observations seem to share a common base that is important for my present argument. They all assume that a garden is temporal and unstable-although disposing of a fixed frame-and is a dynamic "object," and that these characteristics stem from its biological (in the broad sense of the term) and cultural background (see also Miller 2010). Gardens may, then, be defined as "dynamic open aesthetic objects," which means that they do not have a logical structure determining their meaning and the way they should be appreciated, and that they do not have static forms intended to endure for as long as possible (Fenner 2006).

In other words, although we have an idea of a garden as a historical monument that should be approached historically, we also believe that a garden is something living in the double sense of biologically and culturally. By adding these two concepts we can arrive at something resembling the Romantic idea of a living work of art. We may find this in the official document issued by the International Council on Monuments and Sites, the Florence Charter:

A historic garden is an architectural and horticultural composition of interest to the public from the historical or artistic point of view. As such, it is to be considered as a monument. The historic garden is an architectural composition whose constituents are primarily vegetal and therefore living, which means that they are perishable and renewable. Thus its appearance reflects the perpetual balance between the cycle of the seasons, the growth and decay of nature and the desire of the artist and craftsman to keep it permanently unchanged. ... since it is a living monument ... preservation must be governed by specific rules. ... As the expression of the direct affinity between civilisation and nature, and as a place of enjoyment suited to meditation or repose, the garden thus acquires the cosmic significance of an idealized image of the world, a "paradise" in the etymological sense of the term, and yet a testimony to a culture, a style, an age, and often to the originality of a creative artist (emphasis added; 1981, § 1, 2, 3, 5).

The document clearly illustrates the major problem, without yet offering a univocal solution. The Charter contrasts the historical value of a garden associated with "the desire of the artist and craftsman" whose project should be, if possible, kept "in an unchanged condition [which] requires both prompt replacements ... and a long-term programme of periodic renewal (clear felling and replanting with mature specimens)" (§ 11). The Charter also recommends that the "restoration work must respect the successive stages of evolution of 
the garden concerned. In principle, no one period should be given precedence over any other" ( $\S 16$ ), and warns that "where a garden has completely disappeared or there exists no more than conjectural evidence of its successive stages a reconstruction could not be considered a historic garden" ( $(17)$. Two other related points are worth noticing. Firstly, the document recognizes the value of nature as such, for it states that "by reason of its nature and purpose, a historic garden is a peaceful place conducive to human contacts, silence and awareness of nature" ( $§ 19)$, and that interest in historical gardens should be promoted for they help to build the "awareness of the need for due respect for nature and the historic heritage" ( $§ 25)$. Secondly, a historic garden is "a place of enjoyment suited to meditation or repose," which means that its present function or value need not correspond with its original for rarely were gardens treated this way in the past.

Thus, the idea of a living-again, both biologically and culturallymonument may appear to be contradictory, and it probably is. A similar trait, but in the context of ruins and monuments in general, was discovered by Riegl, who in 1903 published his seminal Der moderne Denkmalkultus, sein Wesen, seine Entstehung [The Modern Cult of Monuments: Its Essence and Its Development]. The significance of his work lies in discriminating and defining principal values connected with monuments. Although he was not interested in gardens, and his main examples are architectural, his remarks shed light on the topic of gardens and landscapes.

Riegl differentiates between two main categories of monuments: "deliberate monuments" and "unintentional monuments." The former include monuments that were intended by their creators to commemorate particular events, deeds, or people. The latter are, in turn, described as follows:

Since the creators of these works, which we consider today as historical monuments, wanted primarily to satisfy certain practical or ideal needs ... and certainly did not as a rule intend to leave evidence of their artistic and cultural life to future generations, then the term "'monument", which we nevertheless use to define these works, can only be meant subjectively, not objectively. We modern viewers, rather than the works themselves by virtue of their original purpose, assign meaning and significance to a monument. In both cases - that of deliberate and of unintentional monuments-a commemorative value exists and for that reason we think of both as "monuments." In both cases, we are interested furthermore in the original, uncorrupted form of the work as it left the hand of its maker, and this is the state in which we prefer to see it, or to which we prefer to restore it in thoughts, words, or images (Riegl 1996, 72).

In other words, both types of monuments (incidentally, we may state that gardens may belong to either of these) are traces of their time, and as such they have a historical value. However, Riegl states, there is still another reason why 
we are interested in works produced by past generations: they make us think of the time that has passed since they were created. In this case he speaks of an "age value," which is as essential as historical value even if it is, so to speak, less discursive since it does not require knowledge, but is a matter of impression. Basing on this scheme, Riegl writes:

The fundamental aesthetic principle of our time based on age values may be formulated as follows: from the hand of man we expect complete works as symbols of necessary and lawful production; from nature working over time, on the other hand, we expect the dissolution of completeness as a symbol of an equally necessary and lawful decay (73).

He then adds that "modern man at the beginning of the twentieth century particularly enjoys the perception of the purely natural cycle of growth and decay" (73). This is also one of the sources of the modern attitude toward landscape and of the idea of treating certain natural phenomena as monuments (83).

Historical value and age value are to a certain extent contradictory, for the former leads people to preserve and restore monuments whereas the latter suggests that such activity amounts to interfering with natural laws. Nevertheless, restoration is necessary, although for reasons other than historical value alone. As Riegl explains it:

Without doubt, the unhampered activity of the forces of nature will ultimately lead to a monument's complete destruction. ... A bare, shapeless pile of stones will not provide the viewer with a sense of age value. For that purpose, at least a distinct trace of the original form, of the former work of man-of the original production-must remain, since a pile of stones represents no more than a dead, formless fragment of the immensity of nature's force, without a trace of living growth (74).

For Riegl, then, the age value cannot overwhelm historical value. In other words, in order to be what it is, a monument has to conserve, at least to a minimum degree, its original shape and so its historical value. Otherwise, the garden is seen merely as a product of natural, but not human, forces. It is then more like a natural monument, which witnesses not human or cultural, but only non-human natural history. On the other hand, the historical value that in theory can be fully restored cannot supplant the age value because whenever this happens-for example, when a monument is fully restored--we lose the impression that we are looking at something coming from the past

There is, still, another type of value that is indissolubly linked with monuments and that adds another dimension to the conundrum: present-day values. Riegl describes them as follows:

Most monuments are also able to satisfy those sensory and intellectual desires of man that could as well (if not better) be 
met by modern creations. ... From the standpoint of present-day value, one tends not to consider a monument as such but puts it on a par with a recently completed modern creation, thus requiring a monument (old) to display the same outer appearance as any work of man (new). ... The conclusion is obvious: if a monument bearing signs of disintegration is to appeal to the modern Kunstwollen [taste], the traces of age must be removed first of all ... and [it has to] appear once again like a newly created work. ... Wherever age value collides with newness value in a monument of continuous use, it will seek as much as possible to resign to newness value, not only for practical considerations ..., but also out of ideal ... $(78,80)$.

In a way, then, present-day value goes hand in hand with historical value as it leads to the restoration of the monument in its original form as if it were a recent creation.

If we apply Riegl's remarks to gardens and juxtapose them with the content of the Florence Charter, it seems obvious that we cannot let nature overcome the original plan or shape of a garden. If that occurs, the result would be not a garden anymore but something like Riegl's "shapeless pile of stones."

A very interesting problem rises here: even if we underline a garden's processual and unpredictable character, the question arises as to what extent these natural processes may remain spontaneous and undirected. To put it simply, at what point does a garden that is unattended by a gardener cease to be what it is, namely a garden, and turn into something else, such as an "exgarden" or a wild landscape? ${ }^{6}$

On the other hand, if we tend to dismiss the age value of a garden and are constantly trying to maintain it as if it were new, we are forgetting something very important.

It is true that an old building acquires its age value because of time, but time is an external factor in the sense that the building lasts despite its influence. This is where the difference between architecture and gardens lies: gardens, like buildings, are influenced by the passage of time, but in this case time is more like a factor that enables gardens to exist. In this sense the temporal dimension is not an external feature that can be removed or whose influence may be somehow diminished, but is an internal element. What is more, the passage of time does not mean only that things will decay, since growth occurs too (incidentally, we may notice that this, according to Riegl, is a source of pleasure for us). In other words, as far as a garden is concerned, the passage of time is not tantamount to it just moving away from its origin as it is in the case of, say, a ruins, which if not conserved would crumble more every

${ }^{6} \mathrm{~A}$ garden which is not cultivated, loses its artful character pretty quickly and turns into "no man's nature." On that topic see Pollan 1991; this is what happened to a large extent to the Krasiński Garden due to decades of neglect. 
year.7 ${ }^{7 h e r e f o r e, ~ t h e ~ t e n s i o n ~ b e t w e e n ~ t h e ~ p a s t ~ a n d ~ t h e ~ p r e s e n t ~ i s ~ i n h e r e n t ~ i n ~}$ the idea of a garden itself to a much greater extent than it is in the case of, say, architecture. But at the same time it has a different character. Its age value stems from the fact that we see that we are in an old garden (judging mainly by the age of the trees), which means that although its original form has suffered with the passage of time, plants have also gradually matured and even decayed. In a word, a garden's age value-as it is implicitly shown by the Florence Charter-springs from the intersection of its cultural history and duration, and of its natural history and continuity. A garden, then, is in between an architectural and a natural monument.

\section{Conclusions}

We may notice that the fully restored Krasinski Garden, in which most of the plants are new, would indeed possess historical value. But this would be an early twenty-first century value that has only an indirect relationship with the garden's original historical value that was planned to be restored. And, no doubt, such a restoration would be directed by present-day values, as Riegl wrote. However, the same holds true for any other approach. If, for example, the Krasinski Garden were not restored in this extensive manner, but left as a halfwild "city nature reserve" as the opponents to the restoration project seemed to wish, it would be an early twenty-first century "unintentional monument" too, likewise distantly based on its origin. But here the trap consists in letting the garden return to unmanaged nature, which would not be wanted for its newness but for other currently held values, such as ecological value. In the former case, ecological continuity is sacrificed for supposedly restored historical value, while in the latter the opposite is true-the historical value is sacrificed for ecological continuity. One way or another, what comes to the foreground are present-day values. This conclusion is unavoidable for both theoretical and practical reasons. Whatever we think or do is a "monument," so to speak, of our age, and the debate regarding the fate of the Krasinski Garden is no different; nonetheless, it tells us a lot about gardens in general. First, it shows that public gardens mean a lot to people who go there to experience nature. Second, the debate proves that gardens are much more complex "things" than one, including garden specialists, might imagine. Moreover, the discourse which excludes an ecological perspective-however naïvely construed-is not socially acceptable. I would add that it cannot be accepted in theory, either. However, reducing a garden to a nature reserve is just as unsatisfactory. The debate has shown that the concept of garden combines inconsistent notions (art vs. nature). In the case of the Krasinski Garden, the "ecoactivist" party was defeated in the sense that the garden will be reopened as a restored artwork in

${ }^{7}$ On the topic of ruins and dialectics of art and nature see also Crawford 1983. 
which-as Riegl said-the traces of age will be removed and it will "appear once again like a newly created work." ${ }^{8}$ However, one might wonder whether these inconsistent notions definitely exclude each other or whether both can be equally accepted. I would opt for the latter under one condition: we depart from the traditional way of thinking about art based on traditional media. It is much more fruitful to compare gardens to artworks designed to change over time, sometimes very radically, or to live their own history recreated by their beholders or visitors. In other words, we should look at gardens through the experience of $20^{\text {th }}$ century art where fixation and change, planning and unpredictability, can successfully coexist. Land art, or ecological art, seems to offer good models for how to reflect on gardens and the relationship between art and nature, seen as "dialectical" (Crawford, 1983) in the sense that neither nature nor art can be excluded since this would lead to the annihilation of an important element of a garden. Moreover, opting for either of them means reflecting upon and taking into consideration the other.

As far as the Krasinski Garden is concerned, I am not persuaded by the implemented solution, which consists in extensive restoration aimed at enhancing historical (and one could add, visual) values, which will dwarf not only the ecological issues but the genius loci as well. I would rather opt for improving the actual shape of the garden by preserving and conserving its natural resources. This would not amount to leaving them untouched (a garden, after all, is not a natural wildlife reserve). Simultaneously, the strategy should include informing visitors about the history of the place and alluding to it by rather small gardening interventions. In this way the authenticity of the place could be maintained, although its origins would be out of sight (but not out of mind).

To conclude, we often think of restoration as an attempt to stop time, or at least to protect objects from the effects of time through restoration. However, even from the perspective of art history, this approach is not as obvious as it may at first seem. Riegl was among those who started this debate, though it has become even more controversial as it is adapted to nature. It can be argued that restoration, conservation, and preservation thus conceived turn natural objects into art-like entities, depriving them of their main component the dimension of time, ranging from geological time to the life spans of individuals. Gardens, being partially natural, are spatio-temporal objects, as are landscapes. And this means the existence of constant change that precludes the possibility of any non-arbitrary treatment of a particular phase of their history as being the most important. As a corollary, it can be said that closing a landscape or garden in the trap of "stasis," and appreciating it as if it were a painting or architecture, is a matter of a particular way of defining what a landscape or

8 This article was written when the restoration works were being conducted at the Krasinski Garden, which was reopened in May 2014. 
garden is. It can stem from, for example, a particular taste. Such an approach, if imposed as the only one, eliminates other approaches as inadequate (see Keekok 1995; Fenner 2003). This was the case with the ecological considerations of the opponents to the project of restoring the Krasinski Garden, which were overcome by historical discourse.

Gardens, like landscapes, endure not despite changes, but because of them. ${ }^{9}$ This is what makes their restorability so problematic. Their restoration is doomed to find, so to speak, the center of gravity that would allow one to find a balance between historical, age, and present values. And this is a very difficult task, if possible at all.

\section{Literature}

Anthony, J. 1996. "Protection for Historic Parks and Gardens". Garden History 24 (1): 3-7.

Antrop, M. 2013. "A Brief History of Landscape Research". In Howard, P., Thompson, I. \& Waterton, E. (Eds.), The Routledge Companion to Landscape Studies. New York, NY: Routledge: 12:21.

Assunto, R. 2005. Il paesaggio e l'estetica. Palermo: Edizioni Novecento.

Berleant, A. 2012. Aesthetics beyond the Arts. New and Recent Essays. Burlington: Ashgate.

Berque A. 2000. Ecoumène. Introduction à l'étude des milieux humains. Paris: Belin.

Brook, I. 2013. "Aesthetic Appreciation of Landscape. In Howard, P., Thompson, I. \& Waterton, E. (Eds.), The Routledge Companion to Landscape Studies. New York, NY: Routledge: 108-119.

Carlson, A. 2009. Nature and Landscape. An Introduction to Environmental Aesthetics. New York, NY: Columbia University Press.

Conan M. (Ed.). 1999. Perspective on Garden Histories. Washington D.C.: Dumbarton Oaks Research Library and Collection.

Cooper, E. 2006. A Philosophy of Gardens. Oxford: Oxford University Press.

Crawford D. 1983. "Nature and Art: Some Dialectical Relationships". The Journal of Aesthetics and Art Criticism 42 (1): 49-58.

Elliot, R. 1997. Faking Nature. The Ethics of Environmental Restoration. London: Routledge.

Fenner, D. E. W. 2006. "Environmental Aesthetics and the Dynamic Object". Ethics and the Environment 11 (1): 1-19.

-. 2003. "Aesthetic Appreciation in the Artworld and in the Natural World". Environmental Values 12: 3-28.

${ }^{9}$ What comes to mind as an apt metaphor is the Bergsonian snowball, which rolling down a hill gets bigger and bigger, adding subsequent layers of snow to its frozen nucleus. 
Hunt, J.D. 2000. Greater Perfections: The Practice of Garden Theory. Philadelphia: University of Pennsylvania Press.

Keekok, L. 1995. “Beauty for Ever?”. Environmental Values 4: 213-225.

Leddy, T. (Interviewee) \& R. Wittaker (Interviewer). 1999. Is This A Garden?

[Interview transcript]. Retrieved from:

http://www.conversations.org/story.php?sid=41\#sthash.0VSVi3Gb.dp uf

Mackellar Goulty, Sh. 1993. Heritage Gardens. Care, Conservation and Management. London-New York: Routledge.

Miller, M. 1993. The Garden as an Art. Albany, N.Y.: Sunny Press.

—. 2010. "Time and Temporality in the Garden". In O'Brien, D. (Ed.), Gardening: Cultivating Wisdom. Oxford: Blackwell: 178-191.

Moore, R. 2009. "Appreciating Natural Beauty as Natural". Journal of Aesthetics Education 33 (3): 42-60.

Parsons, G. 2008. Aesthetics and Nature. London: Continuum.

Pollan, M. 1991. Second Nature: A Gardener's Education. New York, NY: Atlantic Monthly Press.

Riegl, A. 1996. "The Modern Cult of Monuments: Its Essence and Its Development". In Stanley Price, N., Talley, N. K., \& Melucco Vaccaro, A. (Eds.), Historical and Philosophical Issues in the Conservation of Cultural Heritage. Los Angeles: Getty Conservation Institute: 69-83.

Ross, S. 1998. What Gardens Mean? Chicago: Chicago University Press.

Scruton R. 2000. Perictione in Colophon: Reflections on the Aesthetic Way of Life. South Bend, Ind: St. Augustine's Press.

Treib, M. (Ed.). 2011. Meaning in Landscape Architecture and Gardens. New York: Routledge.

ELC. 2000. European Landscape Convention. Retrieved from: http://conventions.coe.int/Treaty/en/Treaties/Html/176.htm

Krasinski. 2013. Retrieved from: http://www.ogrodkrasinskich.pl/

FCh. 1981. Florence Charter. Retrieved from:

http://www.icomos.org/charters/gardens_e.pdf 
Mateusz Salwa (Warsaw University)

\title{
Historic Gardens as Places of Conflicting Values
}

\begin{abstract}
The aim of the article is to present historical gardens as phenomena inevitably pervaded by an ongoing clash of values. The conflict stems from the twofold character of gardens where art (or in broader terms: culture) and nature are combined, which results in a tension between the tendency to remain static and durable that human culture seeks, and the changeability and dynamics that are inherent in nature. This conflict can be characterized by referring to a theory proposed by Austrian art historian Alois Riegl, one of the founders of modern monument restoration theory who identified three types of values associated with monuments: historical value, age value, and present-day values. What is more, one can assume that gardens can be treated as particular tokens of landscape. Thus, the conflict of values within a garden may be seen as a more limited example of the same clash going on at the more general level of landscape. The argument is illustrated by a short case study of the recent debate over the restoration of the historic Krasinski Garden in Warsaw, Poland.
\end{abstract}

Key words: Gardens, restoration, Alois Riegl, ecology, value conflict, history of art

Ethics in Progress (ISSN 2084-9257). Vol. 5 (2014). No. 1. pp. 96-112.

doi:10.14746/eip.2014.1.6 